\title{
Assessment of Micro-Ice Particles Growth in Laminar Falling Film
}

\author{
Musa M. Radwan ${ }^{1}$ and Nageeb Salem Rodwan ${ }^{2}$ \\ ${ }^{1}$ University of Tripoli, Department of Petroleum Engineering, Tripoli, Libya \\ ${ }^{2}$ Head of Drilling Section, Waha Oil Company, Tripoli, Libya
}

\begin{abstract}
A Numerical model to investigate the heat transfer characteristic of a phase change material slurries (PCMS) flow over a cooled isothermal surface has been developed. The energy equation governs the heat transfer process includes the source term which accounts for the growth of the phase change material particles which are suspended in the heat transfer fluid to form of phase change materials slurries, PCMS. A fully developed velocity profile has been assumed to model the flow of thin constant falling film of suspensions. In this model the thermo-physical properties of the slurries are calculated based on their effective values which are function of phase change particles concentration. The main features of this work are that the phase change slurries show a binary behavior, i.e. they either in the frozen or melting state and are exposed directly to the water based solution without encapsulation. Parameters that influence the heat transfer characteristics are found to be the volumetric concentration of phase change suspensions, Nusselt number of the flow, PCM Nusselt number $(N U p)$. The numerical results have showed that, heat transfer has been augmented due to the growth rate of phase change materials particles concentration.
\end{abstract}

Keywords: Falling Film, Flow of Suspension, Heat Transfer, Phase Change

\section{Introduction}

It is well known that augmentation of heat transport can be achieved using slurry flow, especially if the dispersed particles involve a change of phase [5]. Several mechanisms responsible for this enhancement were examined, including particle rotation in shear flow, particles migration in laminar and turbulent flow, and the role of latent heat in increasing the heat transfer coefficient. Recently phase change materials slurries in particular ice have been used extensively in energy storage, district cooling and control systems. The major attractive factors that make phase change material useful are (a) a high-energy storage density due the absorption or release of latent heat during the phase change process, (b) small temperature variation due to energy absorption at approximately constant temperature, (c) low pumping power requirements due to the increased heat capacity,(d) high heat transfer rates due to large ratio of surface area to the volume of the assumed spherical particles of the phase change suspensions. As a result a wide variety of applications have been suggested and implemented in practice [3]. Over the past decade several techniques of utilizing phase change material in energy storage and thermal control systems have been investigated [4]. In these techniques the phase change material is microencapsulated and suspended in a heat transfer fluid to form phase- change slurry. With all the preliminary studies have concentrated on encapsulating the phase change material, as a heat transfer and storage medium, data for using phase change materials in binary fluids without encapsulating them had received little attention. A numerical model to approximate the rate of ice crystal growth on a cooled vertical plate has been proposed [14] to study the growth of ice particles suspended in a super-cooled liquid film, by regarding them as equivalent heat sources, distributed homogeneously in a water based solution. Fully developed fluid velocity was assumed in their analysis, the increase of particle size (concentration) and variable effective thermo physical properties of the slurry along the plate were considered. In their study, the effects of controlling parameters on heat transfer enhancement were also discussed. In this paper, the thermal performance of phase change materials slurry flowing over a cooled isothermal surface is studied numerically. The numerical model is developed to include the phase change as a source term in the governing energy equation, and uses small Stefan 
numbers to simulate some previous existing literature data as means of validation. The model is intended to investigate the thermal performance of phase change slurry for cool thermal energy storage applications.

\section{Model Development}

Several assumptions are used for the model shown schematically in Fig. 1, including incompressible laminar fully developed flow and spherically shaped particles of phase change materials ,pcm,. The fluid properties are assumed constant except for the effective values of thermal conductivity, viscosity, thermal diffusivity, and specific heat due to the interactions between the pcm particles and the host fluid. The flow is assumed Newtonian which is approximately the case for volumetric concentration of phase change material slurry less than 25 percent [7]. The phase change materials are assumed to be homogeneously distributed in the flow field and the densities of the fluid and pcm particles are assumed equal. Briefly, the model considers the pcm suspensions as well-dispersed heat sources in the falling film. Heat is transferred from the suspended pcm to the super cooled fluid and to the plate surface, and the subsequently generated solid phase (particle size increase) is maintained at the freezing temperature of the solution. In the present study, the inlet temperature of the slurry was set at the initial freezing temperature of the solution, and axial diffusion is neglected in the governing energy equation. Only the constant temperature condition on the plate surface is considered here. Neglecting radiant and evaporative gains and losses, the governing equations and boundary conditions are: The fully developed velocity profile [6] is:

$$
u=\frac{g h y}{v_{e}}\left(1-\frac{y}{2 h}\right)
$$

Where, $\mathrm{u}$ is constant in the lengthwise $\mathrm{x}$ - direction and $\mathrm{v}$, perpendicular to the plate in the $\mathrm{y}$ direction, is assumed to be negligible. The governing steady state energy equation is:

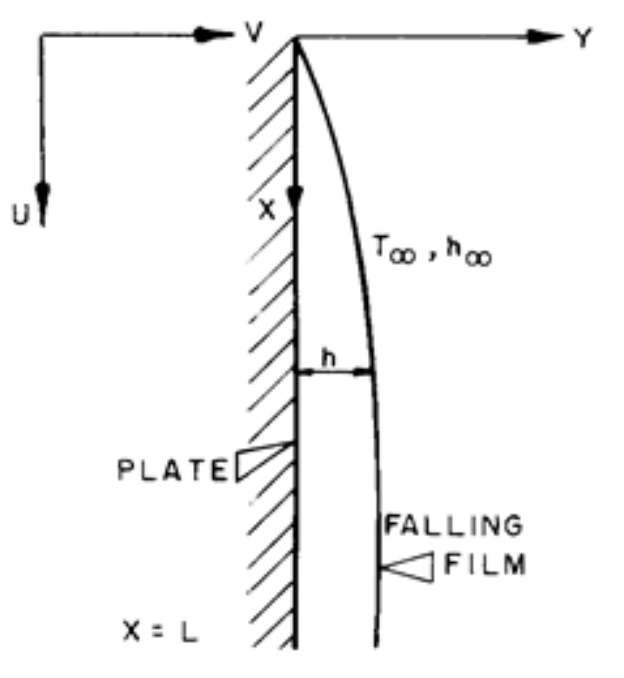

Fig.1 Falling Film Model of PCMS

$$
\rho c_{e} u \frac{\partial T}{\partial x}=\frac{\partial}{\partial y}\left(k_{e} \frac{\partial T}{\partial y}\right)+S
$$

The associated boundary conditions are:

$$
\begin{array}{r}
\mathrm{T}(\mathrm{x}, 0)=\mathrm{T}_{\mathrm{w}}, \\
\mathrm{T}(0, \mathrm{y})=\mathrm{T}_{\mathrm{m}}=\mathrm{T}_{\mathrm{in}},
\end{array}
$$




$$
\mathrm{k}_{\mathrm{e}} \frac{\partial \mathrm{T}(\mathrm{x}, \mathrm{h})}{\partial \mathrm{y}}=\mathrm{h}_{\infty}\left(\mathrm{T}(\mathrm{x}, \mathrm{h})-\mathrm{T}_{\infty}\right)
$$

Where, $\mathrm{T}_{\mathrm{m}}$ and $\mathrm{S}$, are the freezing temperature of the pcms and phase change source term, respectively.

Eq.(5) accounts for the convective heat transfer between the phase change material slurries and the surroundings. The effective bulk dynamic viscosity of the slurry is assumed to be a function of ice crystal volumetric concentration, $\mathrm{C}$, [9] as

$$
\frac{\mu_{\mathrm{b}}}{\mu_{\mathrm{f}}}=\left(1-\mathrm{C}-1.18 \mathrm{C}^{2}\right)^{2.5} ; \quad \mathrm{C} \leq 0.45
$$

and the effective kinematic viscosity is defined as

$$
v_{\mathrm{e}}=\frac{\mu_{\mathrm{b}}}{\rho}
$$

The effective specific heat, $\mathrm{c}_{\mathrm{e}}$, is defined as the mass or volume averaged specific heats of the ice particles and fluid:

$$
\mathrm{c}_{\mathrm{e}}=\mathrm{Cc}_{\mathrm{p}}+\mathrm{c}_{\mathrm{f}}(1-\mathrm{C})
$$

Where, $c_{p}$ and $c_{f}$ are the particle and fluid specific heats, respectively. The effective thermal conductivity, $\mathrm{k}_{\mathrm{e}}$, is related to the bulk fluid thermal conductivity by the relation

$$
\frac{\mathrm{k}_{\mathrm{e}}}{\mathrm{k}_{\mathrm{b}}}=1+\mathrm{BCPe}_{\mathrm{p}}{ }^{\mathrm{m}}
$$

Where the constants, B and $\mathrm{m}$, have the assigned values of 1.8 and 0.18 , respectively, based on the work of [9] and [3] for moderate to large Peclet numbers. The source term, S, of Eq. (2) can be represented as:

$$
\begin{aligned}
& n Q_{p c m}=\rho h_{i f} u\left(\frac{n \pi}{2}\right) d^{2} \frac{\partial d}{\partial x} \\
& \frac{\partial d}{\partial x}=\frac{2 h_{d}\left(T_{m}-T\right)}{\rho h_{i f} u}
\end{aligned}
$$

The local concentration, $\mathrm{C}$, is defined as $\quad \mathrm{C}=\mathrm{n} \frac{\pi \mathrm{d}^{3}}{6}$

\section{Solution Methodology}

Finally, by defining the following dimensionless variables

$$
\begin{array}{lll}
X=\frac{x}{L}, & Y=\frac{y}{h}, & D=\frac{d}{h}, \\
V=\frac{u}{u_{y=h}}, & \phi=\frac{T-T_{w}}{T_{i n}-T_{w}}, & \Gamma=\frac{k_{e}}{k_{b}}
\end{array}
$$

Eqs. (1) - (5), eqs.(11), and (12) become: $\quad \mathrm{V}=2 \mathrm{Y}-\mathrm{Y}^{2}$

$$
\begin{gathered}
\frac{\partial}{\partial \mathrm{X}}(\rho \mathrm{V} \phi)=\frac{\partial}{\partial \mathrm{X}}\left(\eta \Gamma \frac{\partial \phi}{\partial \mathrm{X}}\right)+\frac{\mathrm{L}^{2}}{\mathrm{~h}^{2}} \frac{\partial}{\partial \mathrm{Y}}\left(\eta \Gamma \frac{\partial \phi}{\partial \mathrm{Y}}\right)+\mathrm{S} \\
\phi(\mathrm{X}, 0)=0 \\
\phi(0, \mathrm{Y})=1 \\
\left(\frac{\partial \phi}{\partial \mathrm{Y}}\right)_{\mathrm{Y}=1}=\frac{\mathrm{h}_{\infty} \cdot \mathrm{h}}{\Gamma}\left(\phi_{\mathrm{Y}=1}-\phi_{\infty}\right) \\
\frac{\partial D}{\partial X}=\frac{2 \operatorname{Ste} L}{\rho V u_{h} h c_{f}} h_{d}\left(\phi_{m}-\phi\right)
\end{gathered}
$$




$$
\begin{gathered}
C=\frac{n \pi h^{3}}{6} D^{3} \\
\text { Where: } \eta=\frac{1}{V_{h} \cdot L \cdot c_{e}} ; \text { Ste }=\frac{c_{f}\left(T_{i n}-T_{w}\right)}{h_{\text {if }}} ; \Gamma=1+B C 2^{m}\left(P_{f}(1-y)\right)^{m} d^{2 m} \\
S=\frac{\rho V}{\text { Ste }} \frac{c_{f}}{c_{e}} \frac{\partial C}{\partial X} ; \frac{\partial C}{\partial X}=\left(\frac{n \pi h^{3}}{2}\right) D^{2} \frac{\partial D}{\partial X}
\end{gathered}
$$

The heat transfer coefficient, $\mathrm{h}_{\mathrm{d}}$, between the $\mathrm{pcm}$ and the fluid was determined using the natural convection correlation for spheres as a particle Nusselt number, Nup, $\mathrm{Nu}_{\mathrm{p}}=2 .+0.5 \mathrm{R}_{\mathrm{a}}{ }^{0.25}$

The local plate (wall) Nusselt number is defined as: $\mathrm{Nu}_{\mathrm{x}}=\frac{\mathrm{h}_{\mathrm{x}} \mathrm{x}}{\mathrm{k}_{\mathrm{c}}}$

where, ke, is the effective thermal conductivity of the mixture near the plate surface.

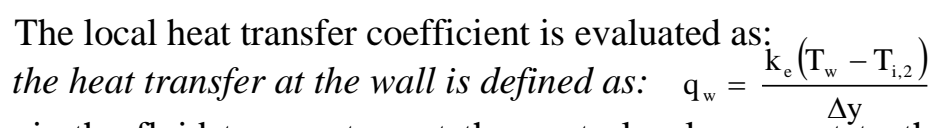

Where $T_{i, 2}$ is the fluid temperature at the control volume next to the wall. Since the source term in the governing energy equation, Eq. (15), is an implicit function of the slurry temperature, the axial and vertical coordinate, and particle diameter distribution, no analytical solution exists and, therefore, a steady-state controlvolume finite-difference approach described by [8] was used to predict the dimensionless temperature, $\phi$, from eq. (15) and pcm particle diameter from eq. (19) throughout the flow field at steady-state conditions. The solution was considered complete when the change in $\phi$ values upon subsequent iterations was less than $10^{-6}$. In this solution methodology the discretized forms of eqs. (15) - (19) are obtained by applying the conservation laws over a finite control volume surrounding each grid node and integrating over the control volume. The harmonic mean of thermal conductivity is used at the control volume faces. The sequence of numerical calculations is identical to that used to solve conventional single-phase problems. The Coupling that exists between the energy and pcm particle diameter equations is accommodated through iteration, and under relaxation. Within the iterative scheme, eqs. (15) - (20) provide necessary descriptions of the temperature fields, as well as the concentration distributions for the evaluation of the effective values of the thermal conductivity, thermal diffusivity, kinematic viscosity, and the specific heat. Supplementary numerical calculations performed on grids ranging from $20 \times 20$ to $75 \times 75$ suggested that satisfactory grid independence could be achieved using a $50 \times 50$ grid. The film thickness in the y direction was modeled as $0.5 \mathrm{~mm}, 0.75 \mathrm{~mm}$, and $1.0 \mathrm{~mm}$ corresponding to Reynolds' numbers of 137,451 , and 1058, respectively. A constant plate length of $1.0 \mathrm{~m}$ was used for all simulations. The inlet diameter of each ice particle, $\mathrm{d}_{\mathrm{in}}$, was $0.025 \mathrm{~mm}$ to initialize the calculations. The phase change temperature of the solution, $T_{m}$, is function of ice particle concentration [2]. A polynomial correlation which relates slurry concentration to the phase change temperature is of the form:

$$
\mathrm{T}_{\mathrm{m}}=\mathrm{a}_{0}+\mathrm{a}_{1} \mathrm{C}+\mathrm{a}_{2} \mathrm{C}^{2}
$$

where the coefficients, $\mathrm{a}_{\mathrm{i}}$, are calculated from the phase diagram of $\mathrm{NaCl}-\mathrm{H}_{2} \mathrm{O}$ system. The continuum formulation and numerical predictions of the present model have been verified through comparison with literature results [9] for the special case of negligible axial diffusion. As a check of the precision of the numerical model, a heat balance was performed for each simulation. The heat balance is between the calculated heat flux at the plate surface and the sum of the heat fluxes from sensible cooling of the film, the latent heat flux from ice growth, and the convective heat flux from the surroundings at the film free surface. In equation form the heat balance is

\section{Results}

$$
Q_{w}=\dot{m} c_{f}\left(T(x, y)-T_{i n}\right)+\rho V_{c r y s t a l} h_{i f} \frac{\partial c}{\partial t}+h_{\infty} A_{\infty}\left(T(x, h)-T_{\infty}\right)
$$

The solutions are presented in terms of the dimensionless particle diameter, concentration profiles, local (wall) Nusselt number, for different isothermal plate temperature (Stefan number), and film thickness. The concentration profiles along the plate length, $x$, in the film for the case of $\mathrm{Tw}=267 \mathrm{~K}$, Tin $=271 \mathrm{~K}$, (Ste $=$ $0.05), \mathrm{h}=0.5 \mathrm{~mm}$, and din $=0.05 \mathrm{~mm}$ are shown in Fig. 2, indicating as expected the greatest increase near the surface of the plate. Figure 3 shows the dimensionless ice particle diameter distribution across the film thickness and for three axial positions along the vertical plate. The figure indicates large increase in the dimensionless ice 
particle diameter near the cold surface and for large axial positions along the plate. In order to investigate the effect of ice particles growth on the augmentation of heat transport, simulations were performed for single phase (zero concentration) and for different values of Stefan number ranging from 0.05 to 0.1 . A slight increase of Nusselt number have been noticed as Stefan number is increased as shown in figure 4. These results give promises for the future use of slurry ice as a heat transfer fluid and hence possible face out of the existing refrigerants that contribute much to the global warming. Figure 5 depicts the variation of local (wall) Nusselt number with the film thickness at different axial positions along the plate, and for constant surface temperature conditions. It is noted that, the local Nusselt number increases with increasing distance along the plate, $\mathrm{x}$, and decreases with increasing film thickness. Figure 6 demonstrate the effect of Stefan number on the ice particles concentrations and hence on the particle size growth. The numerical results are very sensitive to the equation governing the particle growth within the film. The growth of ice particles was related to the degree of super cooling of the fluid, which is increased as the film flows down the plate. A rate equation that may reflect the actual, experimental growth rate of ice particles subject to different supercoolings may significantly affect the results reported here. Also consideration of nucleation and agglomeration of micro suspensions which are not modeled here may further affect the numerical results of the present model. At present there is no available experimental data for growth rates under similar conditions.

\section{Conclusion}

A numerical model has been developed to study thermal performance of ice slurries. The numerical results showed that ice particles growth rate appears to be primarily a function of Stefan number and film thickness (mass flow rate). Nusselt number. Results have showed that phase change material slurries can effectively enhance the heat transfer coefficient and sustain the fluid temperature. Such enhancement of heat transfer coefficient may be utilized in the effective control of surface temperature (wall), and flow rate reduction. Results of the overall heat transfer coefficient showed that heat transfer can be augmented up to $12 \%$ in the case of using ice slurries as a heat transfer fluid. Comparative calculations were performed for different film thicknesses to assess the effect of including axial diffusion in the governing energy equation; it was found that axial diffusion effects were more pronounced (increase of Nusselt number) for the $0.5 \mathrm{~mm}$ and $0.75 \mathrm{~mm}$ film thickness and has less influential effect for larger film thicknesses. In summary, the present results have given promises of utilizing ice slurry as a heat transfer fluid.

\section{References}

[1] Charunyakorn, P., Sengupta, S., and Roy, S. K., 1991, "Forced Convection Heat Transfer in Microencapsulated PhaseChange Marterial Slurries: Flow in Circular Duct,” Int. J. Heat Mass Transfer, vol. 34, pp. 819-832. https://doi.org/10.1016/0017-9310(91)90128-2

[2] Fang, L. J., Cheung, F. B., Linehan, J. H., and Pedersen, D. R., 1984, "Selective Freezing of a Dilute Salt Solution on a Cold Surface,” Journal of Heat Transfer vol. 106, pp. 385-393.

https://doi.org/10.1115/1.3246684

[3] Hale, D. V., Hoover, M. J., and O’Neil, M. J., 1971, "Phase-change materials Handbook,” NASA CR-61363.

[4] Hart, R., and Thornton, F., 1982, "Microencapsulation of Phase-Change Materials," Final Report Contract No. 82-80, Department of Energy, Ohio.

[5] Kasza, K. E., and Chen, M. M., 1985, "Improvement of the Performance of Solar Energy or Waste Heat Utilization Systems by Using Phase-Change Slurry as an Enhanced Heat-Transfer Storage Fluid," Journal of Solar Energy Engineering vol. 107, pp. 229-236.

https://doi.org/10.1115/1.3267683

[6] Levich, V. G., 1962, "Physiochemical Hydrodynamics," pp. 669-672, Engle-wood Cliffs, NJ.

[7] Rutgers, I. R., 1962. "Relative Viscosity of Suspensions of Rigid Spheres in Neotonian Liquids," Rheologica Acta, vol. 2, NO. 4: pp. 305-348. 
https://doi.org/10.1007/BF01976051

[8] Patankar, S., 1980, "Numerical Heat Transfer and Fluid Flow,” Hemisphere Publishing Co., New York. https://doi.org/10.1201/9781482234213

[9] Stewart, W. E., Jr., Kaupang, R. L., Tharp, C. G., Wendland, R. D., and Stickler, L. A., 1993, “An Approximate Numerical Model of Falling-Film Ice Crystal Growth for Cool Thermal Energy Storage," ASHRAE Transactions Research, vol. 99, (Part I), pp. 347-354.

[10] Vand, V., 1948, "Viscosity of Solutions and Suspensions," J. Phys. Coll. Chem., vol. 52, pp. $300-321$.

https://doi.org/10.1021/j150458a001

https://doi.org/10.1021/j150458a002

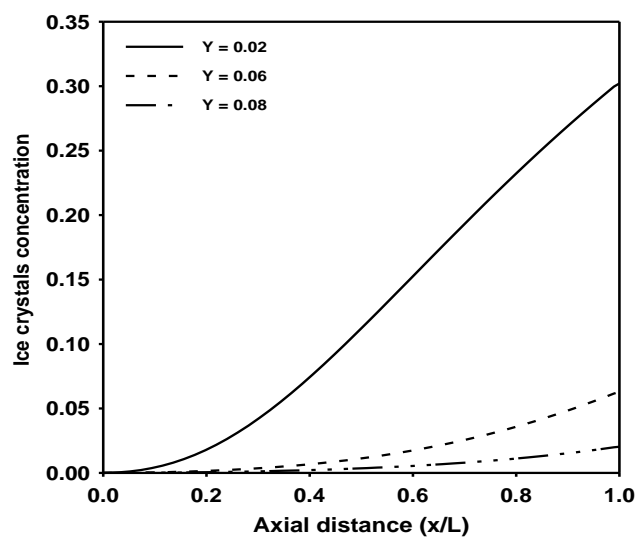

Fig. 2: Ice Particles concentration variation, C.

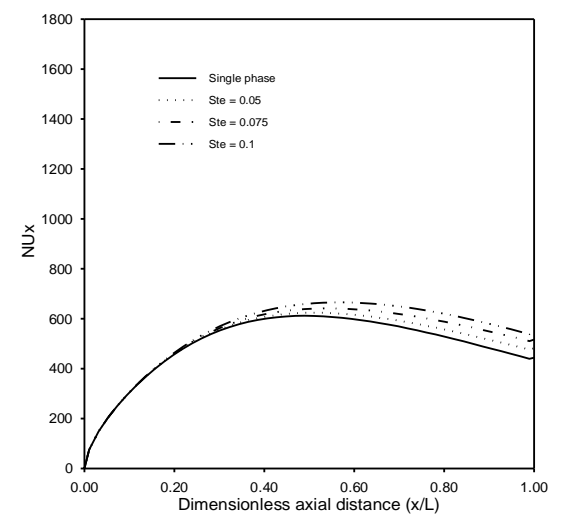

Fig. 4: Nusselt number variation at the plate surface

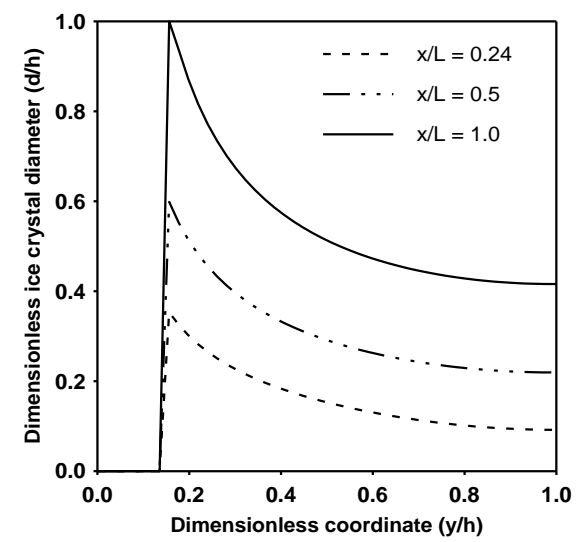

Fig. 3: Particles size variation at different, $\mathrm{x}$, locations

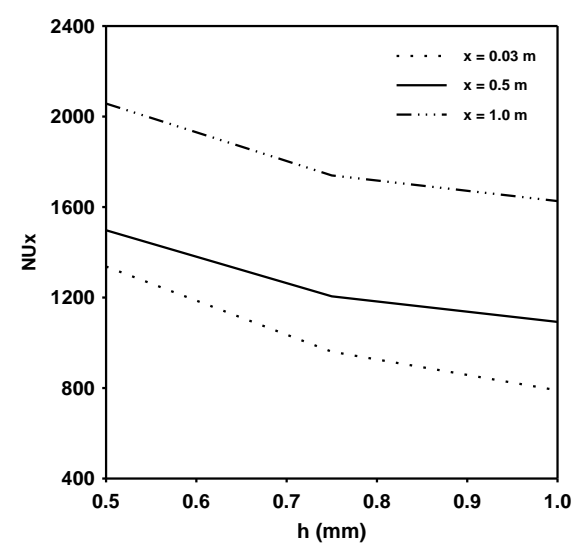

Fig. 5: Nusselt number variation with film thickness

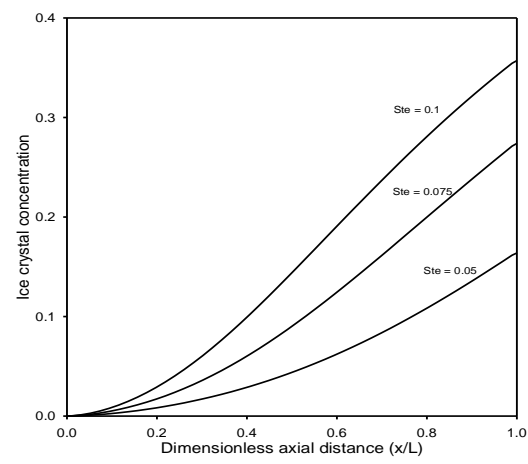

Fig. 6: Effect of Stefan number on ice particle concentration 